allowable cut of softwoods approaches the maximum. He emphasised the advantages of poplar which are short rotations, ability to grow on a variety of sites, response to fertilization and cultivation, and ease of genetic improvement. Dr. Zufa displayed charts showing improved hybrid poplars obtaining three times the diameter, three to five times the height and two to four times the mean annual increment over nat- ural poplar stands on similar sites. The hybrid $\mathbf{P}$. grandidentata $X$ P. Alba at Maple grows more than 1 inch in dbh per year and at 12 years is 14 inches in diameter. Dr. Zufa talked about 20 to 25 year rotations for veneer with 16 to 18 inch $\mathrm{dbh}$ and $80 \mathrm{ft}$ tall trees, and 5 to 10 year rotations for pulpwood.

Following a lively general question period, the over 200 attending the day's proceedings ad- journed to the main cafeteria for a bar and dinner. After dinner Mr. B. Addison spoke as a devoted environmentalist and concluded that North America should set up a workable world government to enforce the limited use of world resources, to control world population and maintain a world wide living standard. We should think, he said, of these goals in regional development schemes.

\title{
Employment and the classes of '72
}

Prompted by Donald James' Can I get a job?, your Editor asked the four forestry faculties with a graduating class if they could supply a breakdown of the employment status of their current graduating year. Of the 194 graduates, at least $70 \%$ appear to have a permanent type of employment. Laval had the largest graduating class, followed by UNB, Toronto and UBC. There is, perhaps, little difference in the percentage distribution of unemployment between the faculties, if some of the unknowns now have, or will soon find, employment. However, if we were to assume that all the unknowns were unemployed, the situation is the reverse of James' findings about the pessimistic east in that the percentage of unemployed decreases the further east one goes.

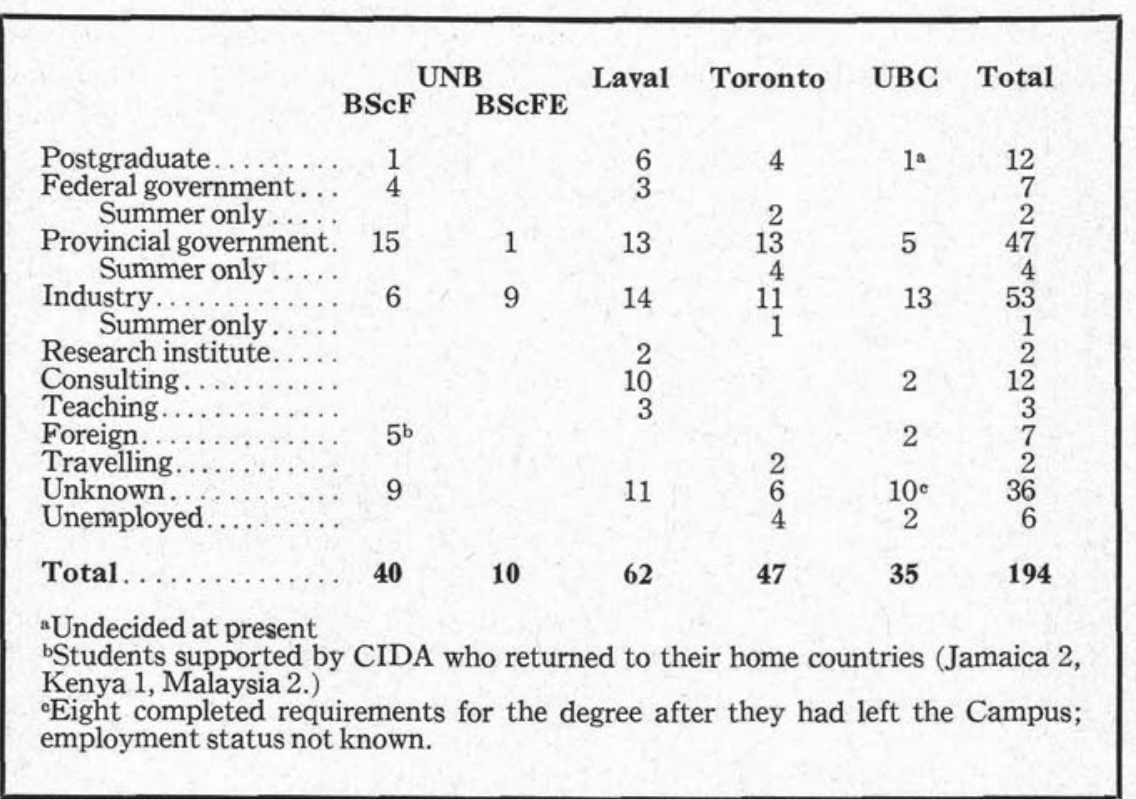

Toronto supplied some information on the employers of the graduates. Of the 13 graduates with a Provincial government, 9 were with the BCFS. This was evidently a one year increase in demand due to the opening of a new forest district plus increased activity in the reforestation and tree improvement programs. Of their 11 graduates with industry, 5 went with Proctor and Gamble who opened a new mill at Grande Prairie, Alberta. It would have been interesting to have known whether the other faculties also supplied graduates to these two employers.

Looking down the figures it will be seen that only Laval and UBC graduates entered the consulting field; Laval and UNB graduates provided the federal government with its "quota". Employment was divided equally between government and industry at $27 \%$ apiece; the three eastern faculties provided a few more to government than industry, whereas UBC provided more to industry. About $10 \%$ of the Toronto and Laval graduates will undertake postgraduate work.

We intend to provide a similar look at the situation next year. 